OPEN ACCESS

Edited by:

Marcella Saade,

Graz University of Technology, Austria

Reviewed by:

Assed N. Haddad,

Federal University of Rio de Janeiro,

Brazil

Changyoon Ji, Independent researcher, Daegu,

South Korea

*Correspondence:

Costantino Menna costantino.menna@unina.it

Specialty section:

This article was submitted to

Sustainable Design and Construction,

a section of the journal

Frontiers in Built Environment

Received: 10 March 2021 Accepted: 22 June 2021

Published: 09 July 2021

Citation:

Vitale P, Alfano V, Pastore T, Menna C, Maffettone $P$ and Asprone D (2021)

Toward a Holistic Rating System: An Attempt to Expand the Boundaries of

Building Sustainability Using SDGs.

Front. Built Environ. 7:679014.

doi: 10.3389/fbuil.2021.679014

\section{Toward a Holistic Rating System: An Attempt to Expand the Boundaries of Building Sustainability Using SDGs}

\author{
Pierluca Vitale ${ }^{1}$, Vincenzo Alfano ${ }^{1,2}$, Tommaso Pastore ${ }^{1}$, Costantino Menna ${ }^{1 *}$, \\ Pietro Maffettone ${ }^{3}$ and Domenico Asprone ${ }^{1}$
}

${ }^{1}$ Department of Structure for Engineering and Architecture, University of Naples, Federico II Via Claudio, Naples, Italy, ${ }^{2}$ Center for Economic Studies CESifo Poschingerstraße 5, München, Germany, ${ }^{3}$ Department of Political Science, University of Naples, Federico II Via Leopoldo Rodinò, Naples, Italy

Several frameworks have been developed for mitigating the environmental impact of human activities. Among them, possibly the most forward-thinking are the Sustainable Development Goals set out in UN Agenda 2030, which are often cited by stakeholders at various levels. Nevertheless, when it comes to policy tools, defining goals relating to sustainability is not straightforward. In this contribution, we use a mathematical framework to compare the goals of Agenda 2030 with the assessments possible with three different building-rating systems, BREEAM, LEED and ITACA. Our results show that these tools address sustainability very differently to the intentions of the SDGs. However, a number of minor changes could easily make the assessments produced by these evaluation systems on this issue more complete.

Keywords: sustainability, sustainable development goals, rating system, mathematical framework, agenda 2030

\section{INTRODUCTION}

The earth is about 4.5 billion years old. Life on the planet will probably become unsupportable in the next 2 billion years, mainly due to a reduction in solar activity (Dalrymple, 1991; Rushby et al., 2013). However, many human activities are gradually, and profoundly, changing its natural evolutionary path, affecting the equilibrium of various marine and terrestrial ecosystems, with a significant loss of benefits and value being the result (Small et al., 2017).

In the last few decades, a number of technical and regulatory tools have been developed in an attempt to address and mitigate the environmental and health impacts of human beings. These include those produced at important global conferences concerning international environmental policies, such as:

- The United Nations Conference on the Human Environment (Stockholm in 1972)

- The World Commission on Environment and Development (Berlin, 1983; also known as the Brundtland Commission, which released the so-called Brundtland Report in 1987)

- The United Nations Conference on Environment and Development (Rio de Janeiro, 1992)

- The Kyoto Protocol, as part of the United Nations Framework Convention on Climate Change (Kyoto, 1997)

These tools for the protection and preservation of the environment and human health, which also seek to maintain economic growth, form the basis of the concept of sustainability. In this viewpoint, "sustainable development" has emerged as one of the key concepts over the last 4 decades. This is 
defined as "development that meets the needs of the present without compromising the ability of future generations to meet their own needs," and aims to build "an inclusive, sustainable and resilient future for people and [the] planet" (Brundtland Report, 1988). Sustainable development can thus be characterized as an attempt to reconcile three important goals: economic growth, social welfare over time, and environmental protection.

In 2015, 17 Sustainable Development Goals (SDGs) were proposed by the United Nations Open Working Group (UNEP, 2019), which are understood as "a universal call to action to end poverty, protect the planet and improve the lives and prospects of everyone, everywhere." The goals were adopted by all UN Member States in 2015 as part of Agenda 2030, which set out a 15-years plan to achieve them. The Member States have been told that the SDGs must be achieved by that date if they are to have the intended results (Willis, 2018). The SDGs are divided into 169 targets, with each of these described by a variety of additional indicators. The targets are general in nature and do not provide a specific model, protocol or roadmap on how the SDGs are to be achieved. Instead, it is up to each Member State to adopt its own specific plan or program (Hák et al., 2016). Holistically, the targets cover all the principles of sustainability at a global level and refer to different aspects of human activities. The targets can be classified as follows:

- Those that aim to preserve or improve environmental conditions, including those pertaining to energy production and use.

- Those that intend to end poverty and hunger through the use of fair and sustainable agriculture.

- Those that promote choices to increase the level and quality of human well-being and health.

- Those that aim to foster policies to improve conditions of peace and justice.

- Those that refer explicitly to cities and take into account both the efficiency and effectiveness of mobility in urban agglomerations. Also considered are the quality and accessibility of infrastructure, especially buildings (Weidema et al., 2018).

It is widely recognized that the construction sector is a key strategic domain at the global level for achieving the SDGs. Housing is not only seen by many as a key element of human security, but is also vital because of what the sector means to the world economy. In Europe, for instance, construction generates almost $10 \%$ of GDP and provides 20 million jobs, mainly in micro and small enterprises (European Commission, 2012). This sector is also pivotal for eventually curtailing environmental burdens, as it currently emits around 39\% of global greenhouse gases (GHG), with a depletion of primary energy of roughly $36 \%$ (IEA, 2019). It also generates approximately $25-30 \%$ of all the EU's waste flows, which consist of materials that include concrete, bricks, gypsum, wood, glass, metals, plastic, solvents, asbestos and excavated soil (European Commission, 2019). Finally, water consumption related to household needs accounts on its own for $12 \%$ of total consumption in Europe, and significantly more if consumption related to the production of materials is also taken into account (Martin et al., 2015).

The data referred to above relate to Europe as a continent, but it is also important to measure consumption on a smaller scale, such as at the level of the single country, conurbation, individual city, specific neighbourhood, and building, and even down to their constituent parts like the materials used to construct them.

Ultimately, then, the sustainability of aggregate units (such as cities) will also depend on the sustainability of the constituent parts (e.g., buildings and urban projects more generally), whether residential or devoted to other uses. It is therefore unsurprising that several green building rating tools or certification systems have been developed over the last 3 decades. These have the purpose of assessing the degree of sustainability of buildings, including residential units and offices, as well as of general infrastructure. Two different methods have commonly been used to develop these tools. The most popular is the bottomup approach, i.e., evaluating effects on a small scale (materials, components, whole buildings) to obtain data to promote sustainability on a larger scale, such as at the neighbourhood level. This has an impact on, and supports, strategies for sustainable development regionally and nationally. Bottom-up approaches can be contrasted with top-down approaches, where the setting of sustainability targets on a larger scale makes it possible to derive targets on a smaller one (Hamedani and Huber, 2012).

Generally, both families of tools involve drafting a weighted scoring system based on different criteria, specific requirements or preconditions (mainly related to environmental performance), with relative levels of compliance rated or rewarded (Vierra, 2019).

Reed et al. (2014) compared 20 global rating tools and then grouped them geographically, distinguishing between those from the United Kingdom and Europe and examples from North America and the rest of the world (Australia, Hong Kong, China, India and Singapore). Their aim was to highlight the strengths and weaknesses of each tool. This was seen as instrumental to a wider goal: identifying a common global rating system that was not tailored to the specific background of a single country and was thus suitable for the world market. Similarly, Nguyen and Altan. (2011) reviewed five rating systems (BREEAM, LEED CASBEE, GREEN STAR and HK BEAM), attempting to determine which of them performed best and were most relevant.

Other authors, like Lee. (2013) and Li et al. (2017), compared rating systems with different schemes to highlight areas of substantial overlap. It has also been identified that BREEAM (Building Research Establishment Environmental Assessment Method), which was originally developed in England and is active in the European market, and LEED (Leadership in Energy and Environmental Design), from the United States, are the most commonly used and comprehensive systems (Ade and Rehm, 2019). Their success can be linked to their "first mover advantage," i.e., the creators were the first to understand the potential demand for such tools in the real estate market (Awadh, 2017). 
Nonetheless, these systems have some weaknesses and, as a result, seem unlikely to be adopted widely. In particular, they do not produce a comprehensive final score that can be assigned to a building, instead assessing them with a set of performance criteria defined in advance. Moreover, despite being portrayed as "multi-issue" tools, the underlying concept of sustainability is defined quite specifically. Additionally, they score a building's performance by comparing it to a benchmark, rather than in absolute terms (Yudelson and Meyer, 2013). Regarding the heterogeneity of the rating systems, Cordero et al. (2020) focused their studies on the need for a common European framework in order to pursue the European directives on sustainability. Illankoon et al. (2017) reviewed eight Green Building Rating Systems (GBRSs) in an attempt to establish seven common key assessment criteria. Several other studies have also highlighted a general lack of concern with wider sustainability, i.e., how "local" benchmarks used to evaluate buildings relate to sustainability on a broader scale. Similarly, Awadh. (2017) compared the characteristics of a number of rating systems and found that while almost all of them are very environmentally oriented, they nevertheless neglect the social and economic dimensions of sustainability, which are considered to be the key pillars of a more encompassing conceptualization. More specifically, rating systems like BREEAM tend to be focused exclusively on energy requirements, while others, such as, LEED, place greater emphasis on indoor environmental quality (IEQ) and materials. Atanda and Ozturk. (2018) treated the need for a holistic perception of sustainability, with rating tools that incorporate social criteria into building assessment, and specifically tried to introduce certain social categories to be considered within the rating system. To this end, Khan et al. (2018) also proposed a variety of rating system (SOBRM) in order to undertake the sustainability approach in a holistic way.

Thus far, it seems reasonable to assume that SDGs could play a crucial role in the development of an integrated framework that includes all aspects of sustainability, coupled with a new globaland lifecycle-oriented rating system (Chandrakumar and McLaren, 2018; Kara et al., 2018; Alawneh et al., 2019; Laurent et al., 2019). However, to achieve this, the SDGs need to be "translated" into a more focused and/or practical form to ensure they are relevant, not only for national governments, but also for the industrial and academic sectors (Muff et al., 2017). Indeed, as reported by Pedersen. (2018), SDGs can be a viable market strategy, with many companies trying to align their core businesses with these goals as a way to manage their environmental impact and, as a consequence, acquire sustainability credentials with customers who are increasingly aware of such issues. Notable examples of such tools are the Global Reporting Initiative (GRI), and "SDG Compass," which has recently been developed by the UN Global Compact and the World Business Council for Sustainable Development (WBCSD) to support the private sector on its path to greater awareness of sustainability and the implementation of relevant measures (Global, 2017).

This paper starts with a holistic consideration of the sustainability principles contained in the UN's SDGs. Our aim is to develop an evaluation matrix for understanding how the three most representative, widely known and widely used examples of a global market rating system-BREEAM, LEED, and the Italian protocol ITACA (Protocollo ITACA, 2004; UNI/ PdR 13, 2019)-approach the issue of sustainability as defined in the SDGs. More specifically, our evaluation matrix enables us to directly compare these systems to determine:

a. Possible areas of overlap between them.

b. The number of targets they cover.

c. How extensively these targets are mapped (reflected with a percentage score).

d. The SDGs that are not addressed at all.

Our evaluation matrix is lifecycle-oriented. A lifecycle assessment (LCA) is a procedure established by the International Standard Organization (ISO, 2006a; ISO, 2006b), and is known for both providing "informed and science-based support to more environmentally sustainable decision-making" (European Commission-Joint R, 2010; Bovea and Powell, 2016) and forming the basis of European Standard EN 15978:2011 on the sustainability of construction work (EN, 2011). An LCA enables the assessment and quantification of the energy usage, environmental burden, and potential impacts of a product/ process/activity throughout its lifecycle, from raw material acquisition to end-of-life.

Our matrix examines the 17 UN SDGs and 169 related targets, representing the latter as distinct benchmarks against which to measure the degree of sustainability of a building, whether residential, office or infrastructure. As depicted in Figure 1, the matrix enables top-down and bottom-up approaches to be adopted at the same time, and considers five spatial-scale levels simultaneously: operator/worker, user/ inhabitant, neighbourhood, city, and world. Moreover, on a temporal level, the matrix presents three additional pieces of lifecycle information for each target, with specific consideration given to the following phases: pre-use (A1A5); use (B1-B7); and end-of-life (C1-C4, D) (CEN, 2013). Figure 1 has two parts, with the upper one describing the spatial scale remodeling of Zeinal, Hamedani and Huber. (2012) on the possible use of a dual approach. From this perspective, the bottom-up method means moving from the (lowest) operator/worker dimension to the (highest) world scale, while the top-down approach, which is usually intended to apply at the city or regional level, has added the world dimension in order to better meet the aims of the SDGs. The lower part of Figure 1 relates to the temporal scale, where we propose the 2013 scheme from the Comité Européen de Normalisation (CEN) and adopt its three-lifecycle stage approach. The pre-use phase (A1-5) is encircled in Figure 1 with a blue line and encompasses all the activities that take place in the stage before a building is utilized. The use phase (B1-B7) is encircled in orange; then, after a building has been used and any maintenance activities have been carried out, the final step is the end-of-life phase $(\mathrm{C} 1-\mathrm{C} 4, \mathrm{D})$, which is encircled with a green line and takes into account the stages involving the decommissioning of a construction. 

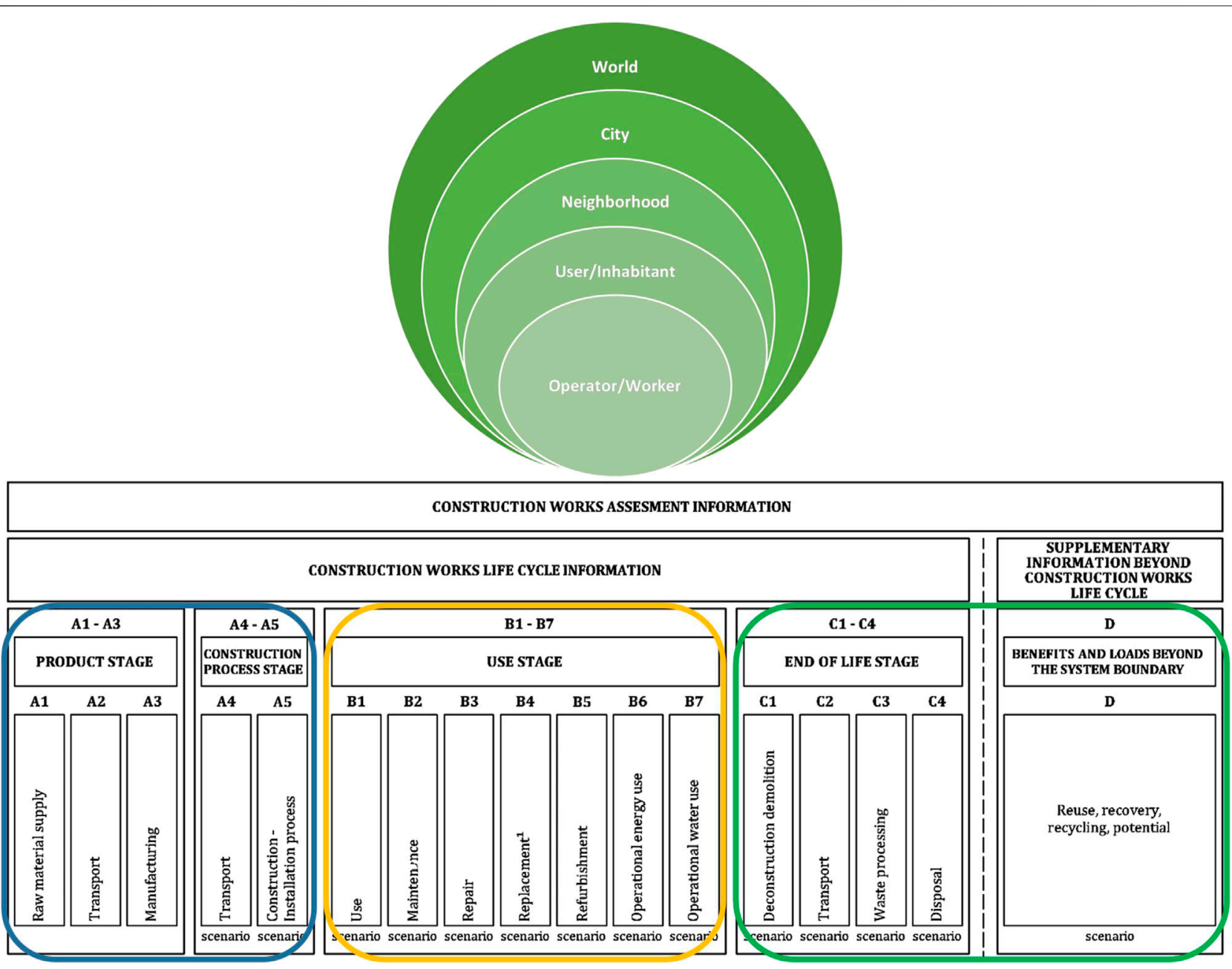

FIGURE 1 | Spatial and temporary information considered in the matrix.

In addition, each target has been subdivided into three further categories-environment, economy and society-based on the Triple Bottom Line (TBL) paradigm, according to which sustainability should be outlined as a return on investment, while shareholder value should include environmental and social dimensions (Slaper, 2011). Taking into account the information mentioned above, the matrix appears as a multidimensional scheme, as depicted in Figure 2. The evaluation matrix has been designed by considering three dimensions, which are: 1) the sustainability pillars (environment, economy and society); 2) the stakeholders (from the operator/worker to the world in general); and 3) the time scale that considers the lifecycle of a building, which typically extends from the pre-use phase, to use phase and up to the end-of-life. The matrix that is applied to each of the 169 targets of the 17 SDGs is the core section of the study, and is necessary to evaluate the coverage level of the GBRSs, in order to understand how they deal with that each target, by considering the TBL, and the stakeholders and part of the lifecycle in question.

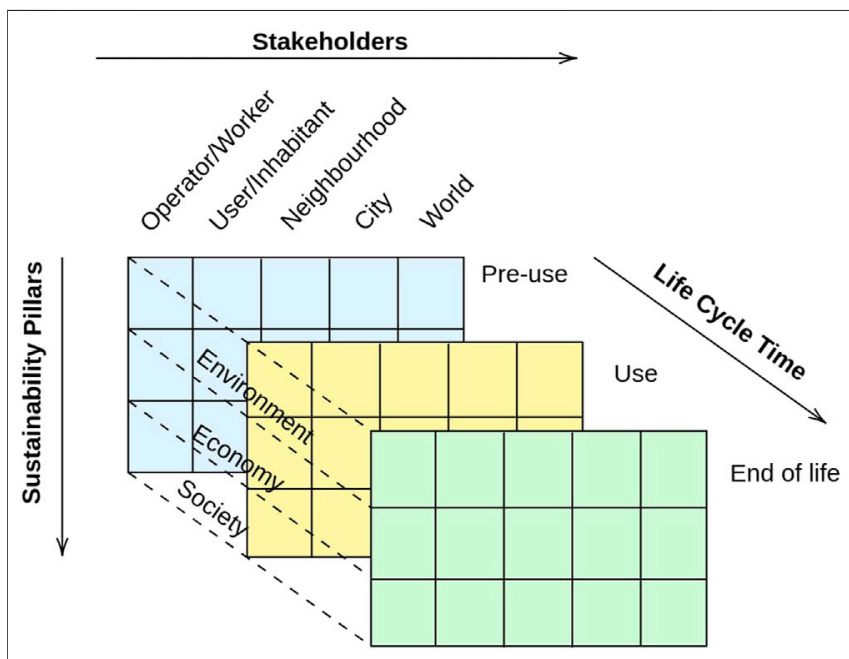

FIGURE 2 | Depiction of the 3D evaluation matrix developed to assess and compare GBRSs. 


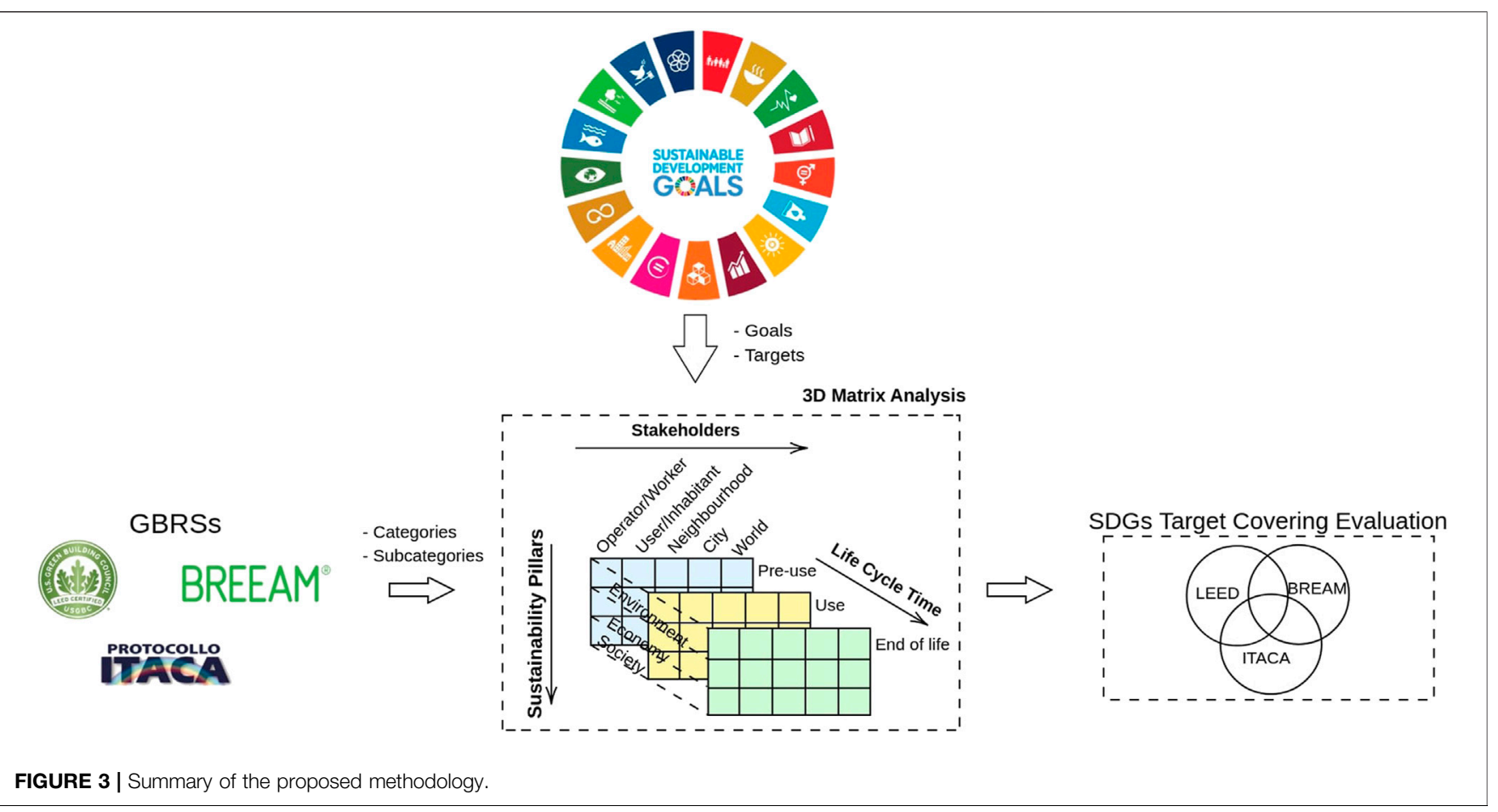

\section{METHOD}

The aim of this work is to assess the distances separating SDGs and some reference GBRSs. To do so, the methodology here presented makes use of a $3 \mathrm{D}$ evaluation matrix that appraises the matching between categories and subcategories of a given GBRS to each of the 169 targets of the 17 SDGs. In particular, as summarized in Figure 3, the 3D matrix derives from a proper mapping of the SDG goals and target. Then, each of the GBRSs considered in this study (BREEAM, LEED, and ITACA) is analyzed through the $3 \mathrm{D}$ matrix to evaluate the covering of its categories and subcategories with respect to the targets of the SDGs. As a result of this evaluation, a covering percentage is reported, and the combinations of the GBRSs (intersection or pairwise-intersection or union) are evaluated. This methodology, thoroughly explained in the remainder of the paper, can be applied to other GBRSs all over the world, in order to evaluate their coverage level and then address their sustainability.

There are several evaluation systems (both private and public) that attempt to measure the sustainability of a building and be applicable across a wide spectrum of intended uses for construction projects. In what follows, the focus is on the BREEAM, LEED and ITACA frameworks; we start with a brief description of each of them. As described in the Introduction, BREEAM and LEED are the most representative, well-known and widely used systems on the global market, which is why they have been chosen as references. We also examine ITACA, which is the recognized rating system in Italy.

Descriptions are instrumental in any initial appraisals of the qualitative features of these systems, including their perceived strengths and weaknesses. Figure 4 therefore sets out the essential framework behind the GBRSs considered here. As stated above, the SDGs contain a list of goals to be achieved by 2030 on a global scale, encompassing countries from the most to the least developed. What distinguishes this UN framework is the universality and transversality of its objectives, which aim for sustainability in a very broad sense. This poses new challenges when it comes to quantifying such wide goals.

\section{Rating Systems \\ Building Research Establishment Environmental Assessment Method}

BREEAM was developed by the Building Research Establishment in the United Kingdom at the start of the 1990s, and became the first GBRS available on the market on a global scale (Marjaba and Chidiac, 2016). It is widely used and covers local codes. It also allows customization for international applications, and is regarded as a flexible tool, partly for this reason (Doan et al., 2017). One of its distinctive features relates to the structure of its accountability procedures, which require the intervention of an assessor to validate the findings submitted by private actors undertaking a construction project.

The structure of BREEAM starts with a request for general information on the building seeking certification, such as its intended use, position, occupants, and a wide variety of more technical details. The core elements of the framework's scoring process comprise a set of categories divided into a variable number of subcategories and related assessment criteria. A better score can be achieved by obtaining a number of prearranged credits (total or partial; in percentage terms) relating to: energy, health and wellbeing; innovation; land use and ecology; materials; management; pollution; transport; and waste and 


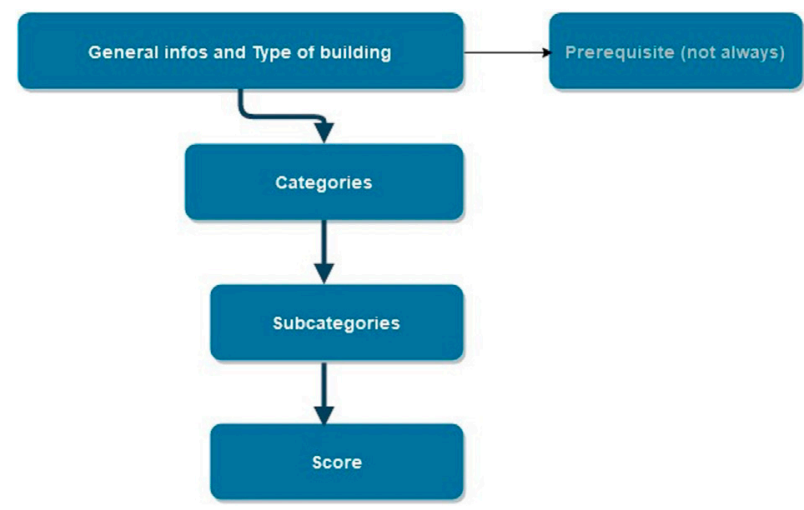

FIGURE 4 | General framework of the GBRSs considered.

water. It is clear from these that the main focus is environmental sustainability.

Another important feature of BREEAM is its provision of different levels of certification based on how many benchmarks have been met by a given construction project. A scheme can be judged by the assessor to be (in ascending order): a. Acceptable (in-use scheme only); b. Pass; c. Good; d. Very good; e. Excellent; and $\mathrm{f}$. Outstanding. Stars are used to codify these different levels and appear on the certificate awarded by BREEAM (www. breeam.com).

\section{Leadership in Energy and Environmental Design}

LEED was developed by the United States Green Building Council (USGBC), which released a pilot version in 1998. The tool was conceived to be voluntary from the time of its inception, and this continues to be the case with the latest iteration (4.1). One of its key features is its flexibility, which makes it suitable for evaluating different construction types. The system is very userfriendly, as it does not require an assessor's validation score and can be compiled on behalf of a construction project by an accredited professional working with a client during the assessment process (Ofori-Boadu et al., 2012). For this reason, LEED was the first GBRS to be acknowledged and adopted worldwide (Ameen et al., 2015).

The structure of LEED is based on a checklist, which includes relatively "rigid" prerequisites in a binary form (pass/fail). Satisfying the items on the checklist is considered to be a necessary condition for certification. A number of construction types can be evaluated with this tool: new construction; schools; and healthcare locations. The framework is organized in eight categories with related assessment criteria, which are evaluated with predetermined scores. The scores are then added together to produce a total weighted outcome. The eight categories are: a. location and transportation; b. sustainable sites; c. water efficiency; d. energy and atmosphere; e. materials and resources; f. indoor environmental quality; g. innovation; and $\mathrm{h}$ regional priority. Like BREEAM, the emphasis of LEED is oriented toward environmental issues. Moreover, here, too, the certification is based on the total score achieved, with the individual scores this is composed of obtained using the different thresholds. The possible outcomes are: a. Certified; b. Silver; c. Gold; and d. Platinum (https://www.gbcitalia.org/leed).

\section{Institute for Innovation and Transparency of Procurement and Environmental Compatibility}

The ITACA (Institute for Innovation and Transparency of Procurement and Environmental Compatibility) protocol was developed within the framework of the Interregional Working Group on Sustainable Construction (IWGSC). Technical support was provided by iiSBE Italia (international initiative for a Sustainable Built Environment Italy) and ITC-CNR (Protocollo ITACA, 2004; UNI/PdR 13, 2019). The system was devised as a way to help Italian regions (formal administrative units) develop a strategy and formal tools to support territorial policies aimed at promoting environmental sustainability in the construction sector. The ITACA protocol is derived from SBTool, which is an international assessment model customized for the Italian context, in particular the characteristics of national environmental legislation.

The scheme includes a general information checklist, which collects various types of project data. It is also possible to choose a more specific checklist, depending on the type of building (residential, school, industrial) being considered. The checklist is divided into assessment categories and subcategories. Each subcategory has a relative weight, and scores range from (1) "Negative" to (5) "Excellent." The weighted score makes it possible to compute a percentage weight for each assessment category. These categories are: a. quality of site; b. resource consumption; c. environmental burdens; $d$. indoor environmental quality; e. maintaining performance during the operational phase; and f. social aspects. Based on these descriptions, ITACA can be viewed as lying somewhere between BREEAM and LEED in its approach: it is a heterogeneous combination of detail and synthesis and, in line with the other two GBRSs discussed here, has a clear focus on environmental issues. As with the other two systems, the total score achieved allows for different "classes" of certification: A+, A, $\mathrm{B}, \mathrm{C}$ and $\mathrm{D}$, where $\mathrm{D}$ represents a construction that is environmentally unsustainable (Asdrubali et al., 2015).

\section{Methodology Used to Compare the Green Building Rating Systems}

In order to minimize any discrepancies that may arise from performing an analysis of the many different aspects of the systems being compared in this article, a single, specific evaluation grid is considered: "New Constructions," which was chosen because it is the most straightforward and widely used. This makes it possible both to assess more effectively the use of the three evaluation systems in the "real world" and to produce better comparisons. All the other grids are, therefore, not part of the study.

The next section of the paper describes the method employed and the assumptions made for the comparative analysis. More specifically, the information obtained via the GBRSs (first in relation to categories, then subcategories and, ultimately, the assessment criteria) and SDGs (the text of each target) is 
sorted into tables or matrices to enable us to examine the similarities and connections between the systems, along with their capacity to fulfill the requirements of the UN goals.

The first step makes it possible both to evaluate any potential overlaps between the different systems in relation to the assessment criteria adopted, and to sort them according to whether or not they have a similar focus (e.g., "water," "energy"). The categories of each GBRS are organized into three different tables, and the 17 SDGs are then mapped on the basis of their relevance to the rating systems most closely-matched theme. An example of this mapping step can be illustrated with SDG 7-"Affordable and clean energy"-which aims to "ensure access to affordable, reliable, sustainable and modern energy for all." This appears to closely match the categories "Energy" in BREEAM, "Energy and Atmosphere" in LEED, and "Resource Consumption" in ITACA. In the next step, once a preliminary connection between the SDGs and the assessment criteria of the three GBRSs is established, an evaluation matrix is created that simultaneously takes the different information into account.

As described above, there are several "sub-goals" for each of the 17 SDGs. These are defined as targets (169 in total) and describe a goal in detail (see Table 1).

The rows in the evaluation matrix refer to the three dimensions of the TBL, i.e., economy, environment and society, while the five columns are derived directly from the features that emerge from the GBRSs and indicate the operational scale. Indeed, some of the GBRSs on the market, including those investigated in this article, are able to focus their analyses on a variety of scales. Consequently, for the purposes of this study, the following five areas were chosen: operator/worker, inhabitants/user, neighbourhood, city and world. For the sake of simplicity, most of the evaluation tools propose an assessment that takes only three scales into account: inhabitant/user, neighbourhood and, less often, city. In our study, however, the operator/worker and world levels are also included to enable us to consider the issue of scalability and identify where the former scale relates to the impact on the production chain in the construction sector, i.e., what ISO 15804 defines as A1-A2-A3-A4-A5 (the pre-use phases). This is crucial, because it means having a global and holistic vision in both spatial and temporal terms, thereby embracing the principles of a lifecycle assessment (LCA).

The evaluation matrix also shows how the GBRSs correspond to the TBL, based on the relationships between a given row (e.g., environment, economy or society) and the assessment categories. This demonstrates whether or not the distribution is balanced across the three spheres, or if there is bias toward a specific one. Given the emphasis on the environment in BREEAM, LEED and ITACA, the expectation was that this line would be the most populated. Furthermore, the analysis also enabled us to explore how the GBRSs correspond to the SDG targets. More specifically, it meant that we could track the extent to which the environmental, economic or social aspects of each target are taken into account. Populating the matrix with easily recognizable information required us to condense and identify acronyms for the assessment categories related to each GBRS. Tables 2-4 are examples, listing the acronyms for the assessments relating to the "energy" category for the three GBRSs of interest.
One of the first things to emerge from a comparison between the GBRSs and SDGs is the greater level of detail and specificity in the former. This is largely unsurprising, given that the rating systems were designed with a smaller and more focused scale in mind. Nevertheless, the difference in the nature and initial intended goals of the GBRSs and SDGs poses a challenge when it comes to explaining the extent to which the former correspond to the space occupied by the latter.

The system of evaluation in BREEAM is structured on three levels, the first being the category under investigation, namely "Energy". In the second level, the category is then further divided into subcategories, with examples being "ENE 01 Reduction of energy use and carbon emission" and "ENE 02 Energy monitoring". Then, in the third level, assessment criteria are available to evaluate the performance in each subcategory, i.e., the individual elements that the system requires to be met to determine how compliant a building is and subsequently obtain the credits needed for certification. Prerequisites may relate to the "building floor area," for example, or could include a request such as "Where specified, please confirm the energy production from onsite or near site energy generation technologies".

Something similar can be seen in the ITACA protocol, which also has three levels. In this version of a GBRS, the reference category for energy, for instance, is known as "Resources consumption," and has subcategories that refer to "Primary energy consumption during the life cycle of the building;" the subsequent level, meanwhile, refers to assessment criteria like "Amount of energy from fossil fuels." LEED has a different type of structure, which is simpler and has two levels. A relevant example in this tool is the "Energy and Atmosphere" category, which provides a list of assessment criteria, as well as prerequisites.

The explanations of our investigation thus far are valuable if we are to better understand the information required in the matrix given the twin objectives of: describing the high level of detail specified in each GBRS, and ensuring that this adequately reflects the more generic aims set out in the SDGs targets. Nevertheless, as explained later in more detail, it is important to note that our overall approach was one of generous inclusiveness. Table 4 summarizes Tables 1-3 and, where possible, uses the acronyms employed in Figure 5. In particular, it demonstrates which of the assessment criteria in the different GBRSs align with a specific SDG target (e.g., target 7.2: "By 2030 , increase substantially the share of renewable energy in the global energy mix"). The table also shows how the targets are distributed within the matrix, or which of the three lines-economy, society or environment-are covered by the assessment criteria. In this specific case, the environment line is the most densely populated.

In addition, there are brackets containing three digits with a value of 0 or 1 in each position in the matrix. These numbers represent the three different life-cycle stages, pre-use, use and end-of-life, where: (1 00 ) means that the assessment criteria reported in the table are only designed to measure the impact during the pre-use phase; $\left(\begin{array}{lll}0 & 0 & 1\end{array}\right)$ means that the criteria refer to the end-of-life stage only; and $\left(\begin{array}{lll}0 & 1 & 0\end{array}\right)$ signals that they are designed to measure the impact solely during the use phase. These are given the name "LC coordinates." Clearly, some "positions" will be determined by the nature of the cell in which the coordinates appear. To illustrate this using the operator/worker 
TABLE 1 | Example of the targets relating to SDG 7

Goal 7. Ensure access to affordable, reliable, sustainable and modern energy for all

7.1 By 2030, ensure universal access to affordable, reliable and modern energy services

7.2 By 2030 , increase substantially the share of renewable energy in the global energy mix

7.3 By 2030, double the global rate of improvement in energy efficiency

7.a By 2030, enhance international cooperation to facilitate access to clean energy research and technology, including renewable energy, energy efficiency and advanced and cleaner fossil-fuel technology, and promote investment in energy infrastructure and clean energy technology

7.b By 2030, expand infrastructure and upgrade technology for supplying modern and sustainable energy services for all in developing countries, in particular the least developed countries, small island developing states and landlocked developing countries, in accordance with their respective programs of support

TABLE 2 | Acronyms for the BREAM rating system.

\section{BREEAM}

\section{Energy}

Ene 01 Reduction of energy use and carbon emissions

Ene 02 Energy monitoring

Ene 03 External lighting

Ene 04 Low carbon design

Ene 05 Energy efficient cold storage

Ene 06 Energy efficient transportation systems

Ene 07 Energy efficient laboratory systems

Ene 08 Energy efficient equipment

Ene 09 Drying space

Table $\mathbf{3}$ | Acronyms for the LEED rating system.

\section{LEED}

\section{Energy and atmosphere}

Fundamental commissioning and verification

Minimum energy performance

Building-level energy metering

Fundamental refrigerant management

Enhanced commissioning

Optimized energy performance

Advanced energy metering

Demand response

Renewable energy production

Enhanced refrigerant management

Green power and carbon offsets

column as the pre-use phase (which, as mentioned above, refers more strictly to the production chain of a building component), the expectation is that the first of the three digits $\left(\begin{array}{lll}1 & 0 & 0\end{array}\right)$ will be present in the table. Similarly, if the inhabitant/user column is considered, it is anticipated that the second digit will take the value of 1 , reflecting the use phase on a temporary basis. However, these general patterns do not rule out the possibility that two, or even all three, digits may be present together in a given cell.

\section{RESULTS}

\section{Comparative Analysis and Alignment With the Sustainable Development Goals}

We conducted a number of calculations in relation to the various descriptive statistics derived from the matrix to analyze how the three
TABLE 4 | Acronyms for the ITACA rating system.

\section{ITACA}

\section{Resource consumption}

Primary energy during building life-cycle

B.1.2 Total non-renewable primary energy IT B 1.2

B.1.3 Total primary energy

Energy from renewable sources

B.3.2 Renewable energy for thermal use IT B 3.2

B.3.3 Renewable energy produced within the site for electricity IT B 3.3

evaluation protocols align with the 17 SDGs. As discussed previously, each SDG has been assigned a number of targets by the UN. In the paradigm adopted here, each single target (or subgoal) is spread across 45 different cells, obtained as the Cartesian product of the three dimensions of the TBL, i.e., economy, environment, society. The five columns are derived from the particular GBRS, and the three life-cycle stages are evaluated as shown in Figure 2. Consequently, taking Table 5 as an example, the six different subgoals of goal 1 (G1) yield a total of $6 \cdot 45(=270)$ cells. The matrix then calculates the correspondence of each and any of the GBRSs (presented in Table 5) with each and any of the SDGs. This correspondence/ coverage is reported in both absolute, i.e., the number of cells covered for that specific goal ("Covered" in Tables 5,6), and percentage terms ("Pct."), where:

$$
\text { Pct. }=\left(\frac{\text { Covered }}{\text { cell Total }}\right) \cdot 100 \text {, defined } \forall \text { SDG. }
$$

Moreover, to better assess the power of the coverage of the rating systems and their inter-relationships, we also considered other combinations. Borrowing union and intersection operators from set theory, the union value expresses the share of cells covered by any of the three rating systems included in the analysis, considered jointly (Table 5); meanwhile, the intersection values report the share of cells that correspond simultaneously to the three GBRSs ("All" in Table 7). Finally, Table 7 shows the coverage capacity of any possible pairwise combinations of the three systems. While union can be interpreted as a measure of how well, in general, the GBRSs address the issue of sustainability as defined in the SDGs, intersections are a measure of the degree to which each SDG is vital for a rating system, (with the assumption being that, if addressed at the same time by the three GBRSs, an SDG is likely to be very important for the systems overall). 


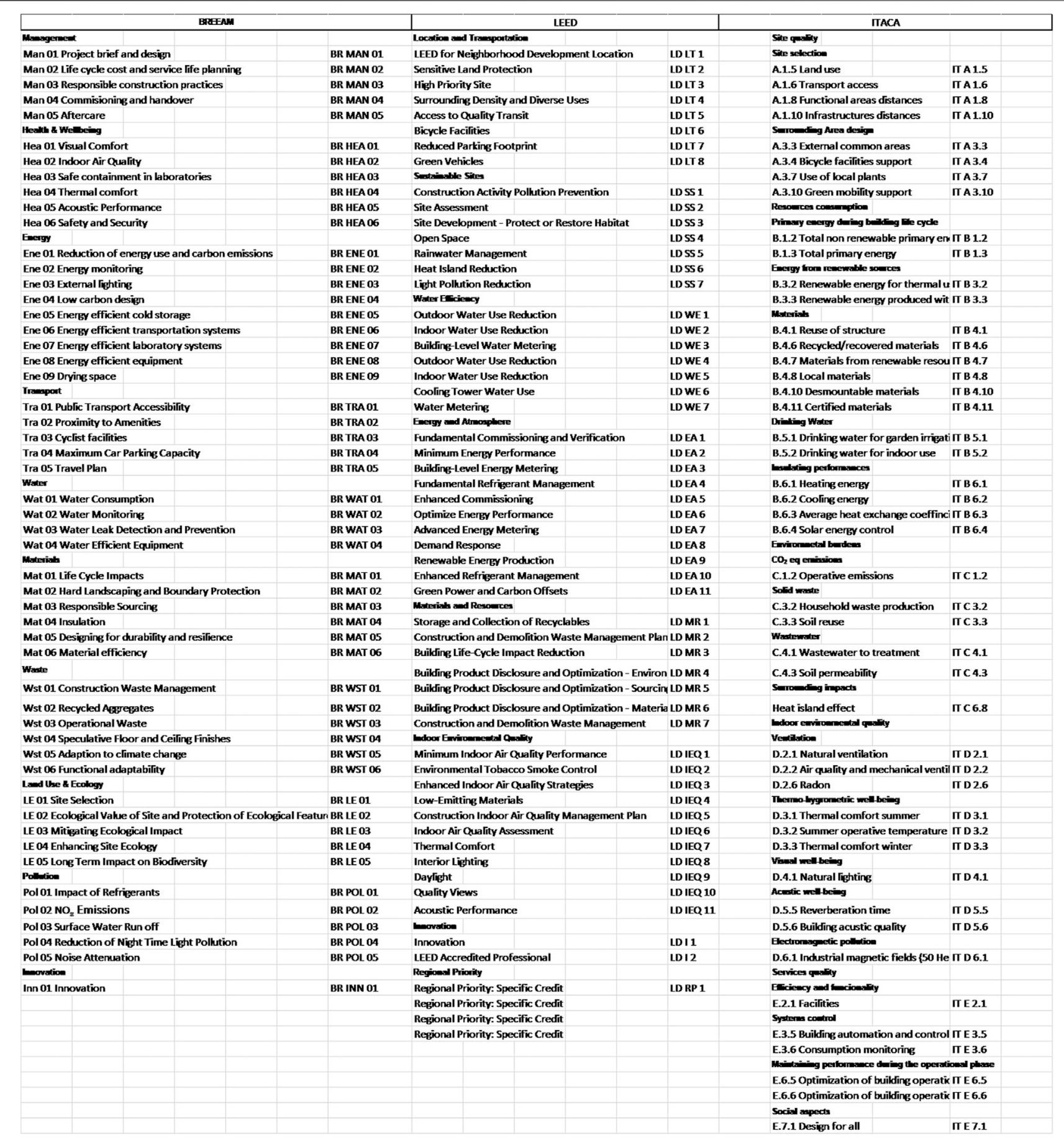

Comparing Leadership in Energy and Environmental Design, Building Research Establishment Environmental Assessment Method and Institute for Innovation and Transparency of Procurement and Environmental Compatibility

Table 7 highlights how the different rating systems align with the indicators in the matrix, while also comparing them with each other. LEED is the best-performing system of the three from the point of view of how well the SDGs are covered: it has a mean of $5.48 \%$ (vs. $3.29 \%$ for BREEAM and $2.13 \%$ for ITACA), and a median of $3.70 \%$ (0 for both BREEAM and ITACA). This is probably due to the more holistic approach adopted by LEED. Indeed, even with very low values in several rows, this system manages to cover all 17 SDGs. This is not the 
TABLE 5 | Summary of tables, with target 7.2 as the example.

\begin{tabular}{|c|c|c|c|c|c|}
\hline $\begin{array}{l}7.2 \text { By } 2030 \text {, increase substantially the share } \\
\text { of renewable energy in the global energy mix }\end{array}$ & Operator/worker & Inhabitant/user & Neighbourhood & City & World \\
\hline \multirow[t]{2}{*}{ Economy } & LD EA $9\left(\begin{array}{lll}1 & 0 & 0\end{array}\right)$ & 0 & LD EA 9 (1 110$)$ & LD EA 9 (1 110$)$ & LD EA 9 (1 10$)$ \\
\hline & LD EA 11 (1 0 0) & & LD EA 11 (1 110$)$ & LD EA 11 (1 1 0) & LD EA 11 (1 110$)$ \\
\hline Society & 0 & 0 & 0 & 0 & 0 \\
\hline \multirow[t]{9}{*}{ Environment } & BR ENE $04\left(\begin{array}{lll}1 & 1 & 1\end{array}\right)$ & BR ENE $04\left(\begin{array}{lll}1 & 1 & 1\end{array}\right)$ & BR ENE $04\left(\begin{array}{lll}1 & 1 & 1\end{array}\right)$ & BR ENE $04\left(\begin{array}{lll}1 & 1 & 1\end{array}\right)$ & BR ENE $04\left(\begin{array}{lll}1 & 1 & 1\end{array}\right)$ \\
\hline & LD EA 1 ( $\left.\begin{array}{llllllllllll} & 0 & 0\end{array}\right)$ & LD EA 1 (0 10 0) & LD-LT 2 (1 111 1) & LD EA 9 (1 110$)$ & LD EA 9 (1 110$)$ \\
\hline & LD EA $1\left(\begin{array}{lll}1 & 0 & 0\end{array}\right)$ & LD-EA-9 (0 10 0) & LD-EA 9 (1 110$)$ & LD EA 11 (1 110$)$ & LD EA 11 (1 110$)$ \\
\hline & LD EA $2\left(\begin{array}{lll}1 & 0 & 0\end{array}\right)$ & LD EA $11\left(\begin{array}{lll}0 & 1 & 0\end{array}\right)$ & LD EA $11\left(\begin{array}{lll}1 & 1 & 0\end{array}\right)$ & & \\
\hline & LD EA $3\left(\begin{array}{lll}1 & 0 & 0\end{array}\right)$ & IT B $1.2\left(\begin{array}{lll}1 & 1 & 1\end{array}\right)$ & & & \\
\hline & LD EA 9 (1 0 0 0) & IT B $3.2\left(\begin{array}{lll}1 & 1 & 1\end{array}\right)$ & & & \\
\hline & LD EA 11 (1 00 0) & IT B 6.4 (1 11 1) & & & \\
\hline & IT B $1.2\left(\begin{array}{lll}1 & 1 & 1\end{array}\right)$ & & & & \\
\hline & IT B $3.2\left(\begin{array}{lll}1 & 1 & 1\end{array}\right)$ & & & & \\
\hline
\end{tabular}

TABLE 6 | Calculation of the alignment of individual GBRSs with the SDGs and their union.

\begin{tabular}{|c|c|c|c|c|c|c|c|c|c|c|}
\hline \multirow[b]{2}{*}{ Goal } & \multirow[b]{2}{*}{ \#Subgoals } & \multirow[b]{2}{*}{$\begin{array}{l}\text { Cell } \\
\text { total }\end{array}$} & \multicolumn{2}{|c|}{ LEED } & \multicolumn{2}{|c|}{ BREEAM } & \multicolumn{2}{|c|}{ ITACA } & \multicolumn{2}{|c|}{ UNION } \\
\hline & & & Covered & Pct. (\%) & Covered & Pct. (\%) & Covered & Pct. (\%) & Covered & Pct. (\%) \\
\hline G1 & 6 & 270 & 1 & 0.4 & 0 & 0.0 & 0 & 0.0 & 1 & 0.4 \\
\hline G2 & 8 & 360 & 13 & 3.6 & 0 & 0.0 & 0 & 0.0 & 13 & 3.6 \\
\hline G3 & 13 & 585 & 27 & 4.6 & 4 & 0.7 & 0 & 0.0 & 30 & 5.1 \\
\hline G4 & 10 & 450 & 6 & 1.3 & 0 & 0.0 & 0 & 0.0 & 6 & 1.3 \\
\hline G5 & 9 & 405 & 12 & 3.0 & 0 & 0.0 & 0 & 0.0 & 12 & 3.0 \\
\hline G6 & 8 & 360 & 48 & 13.3 & 8 & 2.2 & 7 & 1.9 & 52 & 14.4 \\
\hline $\mathrm{G} 7$ & 5 & 225 & 53 & 23.6 & 30 & 13.3 & 18 & 8.0 & 69 & 30.7 \\
\hline G8 & 12 & 540 & 20 & 3.7 & 0 & 0.0 & 0 & 0.0 & 20 & 3.7 \\
\hline G9 & 8 & 360 & 24 & 6.7 & 16 & 4.4 & 16 & 4.4 & 44 & 12.2 \\
\hline G10 & 10 & 450 & 4 & 0.9 & 0 & 0.0 & 0 & 0.0 & 4 & 0.9 \\
\hline G11 & 10 & 450 & 41 & 9.1 & 9 & 2.0 & 55 & 12.2 & 89 & 19.8 \\
\hline G12 & 11 & 495 & 32 & 6.5 & 36 & 7.3 & 23 & 4.6 & 60 & 12.1 \\
\hline G13 & 5 & 225 & 6 & 2.7 & 36 & 16.0 & 1 & 0.4 & 40 & 17.8 \\
\hline G14 & 10 & 450 & 20 & 4.4 & 0 & 0.0 & 0 & 0.0 & 20 & 4.4 \\
\hline G15 & 12 & 540 & 42 & 7.8 & 54 & 10.0 & 24 & 4.4 & 99 & 18.3 \\
\hline G16 & 12 & 540 & 7 & 1.3 & 0 & 0.0 & 0 & 0.0 & 7 & 1.3 \\
\hline G17 & 5 & 225 & 1 & 0.4 & 0 & 0.0 & 0 & 0.0 & 1 & 0.4 \\
\hline
\end{tabular}

case for BREEAM and ITACA, with the former not covering nine goals and the latter ten (as seen above, both systems had a median of 0 ). The SDGs not covered by these two systems (with a score of 0) are: G1 (no poverty), G2 (no hunger), G4 (education), G5 (gender equality), G8 (work and growth), G10 (inequalities), G14 (life below water), G16 (peace and justice) and G17 (partnership).

As suggested above, this is mainly because the assessment criteria in LEED's questionnaire are not very specific, unlike those of both BREEAM and ITACA. Moreover, due to our inclusiveness strategy when compiling the matrix (meaning that we took into account cases where there may, in fact, have been some doubt about their relevance), consideration has been given to some points that LEED touches on only very marginally. For instance, for the first SDG, we aligned LEED's “environment, inhabitant/user" with target 1.5, namely: "By 2030, build the resilience of the poor and those in vulnerable situations and reduce their exposure and vulnerability to climate-related extreme events and other economic, social and environmental shocks and disasters." This decision was made because LEED criterion LD-LT-2 cites "Sensitive Land Protection," and we took the view that this very general reference addressed the SDG target related to reducing the exposure of the most vulnerable parts of society to extreme climate-related events. As can be seen from this example, LEED's greater coverage is mainly due to its more generic system of rating, rather than to any effective greater scope of its protocol.

\section{DISCUSSION}

What is immediately noticeable in the union values in Table $\mathbf{5}$ is that only a few cells are covered in the matrix by the three systems, with very low percentage scores: ranging from $30.67 \%$ 
TABLE 7 | Coverage of the SDGs, as calculated for the intersections: all three GBRSs (ALL) and pairwise intersections.

\begin{tabular}{|c|c|c|c|c|c|c|c|c|c|c|}
\hline \multirow[b]{2}{*}{ Goal } & \multirow[b]{2}{*}{ \#Subgoals } & \multirow[b]{2}{*}{$\begin{array}{c}\text { Cell } \\
\text { total }\end{array}$} & \multicolumn{2}{|c|}{ All } & \multicolumn{2}{|c|}{ BR et IT } & \multicolumn{2}{|c|}{ BR et LD } & \multicolumn{2}{|c|}{ LD et IT } \\
\hline & & & Covered & Pct. (\%) & Covered & Pct. (\%) & Covered & Pct. (\%) & Covered & Pct. (\%) \\
\hline G1 & 6 & 270 & 0 & 0.0 & 0 & 0.0 & 0 & 0.00 & 0 & 0.0 \\
\hline G2 & 8 & 360 & 0 & 0.0 & 0 & 0.0 & 0 & 0.00 & 0 & 0.0 \\
\hline G3 & 13 & 585 & 0 & 0.0 & 0 & 0.0 & 1 & 0.17 & 0 & 0.0 \\
\hline G4 & 10 & 450 & 0 & 0.0 & 0 & 0.0 & 0 & 0.00 & 0 & 0.0 \\
\hline G5 & 9 & 405 & 0 & 0.0 & 0 & 0.0 & 0 & 0.00 & 0 & 0.0 \\
\hline G6 & 8 & 360 & 1 & 0.3 & 1 & 0.3 & 4 & 1.11 & 7 & 1.9 \\
\hline G7 & 5 & 225 & 4 & 1.8 & 12 & 5.3 & 17 & 7.56 & 7 & 3.1 \\
\hline G8 & 12 & 540 & 0 & 0.0 & 0 & 0.0 & 0 & 0.00 & 0 & 0.0 \\
\hline G9 & 8 & 360 & 4 & 1.1 & 8 & 2.2 & 4 & 1.11 & 4 & 1.1 \\
\hline G10 & 10 & 450 & 0 & 0.0 & 0 & 0.0 & 0 & 0.00 & 0 & 0.0 \\
\hline G11 & 10 & 450 & 0 & 0.0 & 0 & 0.0 & 4 & 0.89 & 12 & 2.7 \\
\hline G12 & 11 & 495 & 7 & 1.4 & 18 & 3.6 & 11 & 2.22 & 9 & 1.8 \\
\hline G13 & 5 & 225 & 1 & 0.4 & 1 & 0.4 & 2 & 0.89 & 1 & 0.4 \\
\hline G14 & 10 & 450 & 0 & 0.0 & 0 & 0.0 & 0 & 0.00 & 0 & 0.0 \\
\hline G15 & 12 & 540 & 3 & 0.6 & 12 & 2.2 & 7 & 1.30 & 5 & 0.9 \\
\hline G16 & 12 & 540 & 0 & 0.0 & 0 & 0.0 & 0 & 0.00 & 0 & 0.0 \\
\hline G17 & 5 & 225 & 0 & 0.0 & 0 & 0.0 & 0 & 0.00 & 0 & 0.0 \\
\hline
\end{tabular}

for G7 (energy) to $0.37 \%$ for G1 (no poverty). This suggests that, overall, these approaches do not take sustainability, as interpreted and defined by the UN in its SDGs, into account. The coverage of the SDGs by the three systems is, on average, very low (mean: 8.79\%; median: $4.44 \%$ ). It is also important to remember that these low scores were obtained even though the inclusiveness criterion we adopted was very generous when determining whether a goal was, or was not, addressed by a question. It should also be noted that the union column compares the union of the three different rating systems with the cells in the matrix for the SDG target; this means that these low values are related to the systems overall coverage of the SDGs when considered jointly.

On the other hand, the intersection values in Table 7 show the number of cells covered per goal and target simultaneously by two or more rating systems. More specifically, the column "All" reports the number and percentage score of the cells covered concurrently by the three rating systems, while the subsequent columns refer to the pairwise intersections: BREEAM and ITACA (BR and IT), BREEAM and LEED (BR and LD), and LEED and ITACA (LD and IT). In other words, these measures are intended to show that the same cell is populated with at least one of the assessment criteria from two or more rating systems. The values achieved by the global intersection ("All”) confirm the trend already observed in the union column, with scores of $0 \%$ for 11 of 17 of the SDGs (mean: $0.33 \%$; median: 0 ). The highest values were observed for G7 (energy), with four of the 225 cells covered, yielding a score of $1.78 \%$. As noted previously, this shows that G7 is addressed by the three rating systems. The cross-cutting themes in G12 (sustainable consumption and production), which aims to "Ensure sustainable consumption and production patterns," allowed us to mark the cells corresponding to the subgoals with a broad variety of critical assessments. The references here are to the efficient management of natural resources, the appropriate management of pollutant chemicals throughout their lifecycle and, finally, waste management, including prevention, reduction and recycling. However, although it is impossible to achieve a score of $100 \%$, these values are still very low and reveal a significant distance between the assessment protocols (strictly based on buildings) and the goals and targets set by the UN. Additionally, while the analysis of the global intersection measured the joint agreement of the GBRSs, studying the pairwise intersections enabled us to confirm whether two of the three rating systems were characterized by greater agreement than the third in relation to their coverage of the SDGs. Our analysis revealed that the best coverage was achieved by BREEAM and LEED ("BR and LD"). As seen in Table 5, rather than being evidence of major agreement between the two rating systems, this is instead due to their greater alignment with the SDGs. In fact, while the pairwise intersection "BR and LD" is comparable to "BR and IT" and better than "LD and IT," its coverage is much less than BREEAM and LEED taken singularly. This means that although these two systems generally address the same development subgoals, they often refer to different lifecycle stages or stakeholders.

All of these analyses suggest that the rating systems considered herein and used to measure the sustainability of buildings do not take the concept into account in the same way as the UN, at least in relation to how it defines the SDGs. While the literature has already highlighted some flaws in these systems (Ade \& Rehm, 2019), to the best of our knowledge ours is an original and important critique, since stretching the concept of sustainability and adapting it to specific cases is unlikely to result in any local or global policy having a major impact on the sustainability of life on the planet. On this issue, our analysis highlights a limitation of the current GBRSs, and may, therefore (and hopefully), encourage changes or the creation of a new system more in line with the UN's proposals. Future studies could: extend our analyses to different rating systems; focus on other policies implemented to achieve sustainability in key sectors, such as fishing or farming; or propose an alternative approach that is more in line with the ethos of the SDGs. 


\section{Limitations}

The main limitation of this work is related to the matrix upon which it is based. Indeed, the determination of whether a SDG is addressed by a rating-system criterion was based on a qualitative analysis that, necessarily, involved a degree of subjectivity. The matrix is included as an appendix to this paper. We have attempted to be very inclusive in our approach to avoid the exclusion of any criterion that may be regarded as important. On the other hand, given the diverse logic applied in the creation and use of the analyzed GBRSs, it is difficult to imagine a different classification system.

Another possible limitation is related to the very nature and scope of SDGs and rating systems. The former have been created by the world's most well known and, arguably, influential, intergovernmental organization, and so are accepted as propelling mankind toward achieving a more sustainable planet. However, when all the socio-demographic and economic dimensions are considered, the latter are given a much more limited scope, seen only as having value for assessing the environmental impact of buildings.

Given the important differences in the aims and scopes of BREEAM and LEED, it is also vital to note the degree to which all three GBRSs, jointly, fail to address the SDG cells in the matrix. Indeed, as shown in Table 7, it is possible to take the view that some of the SDGs should not be addressed at all by a rating system designed to assess the sustainability of buildings; the three systems, considered jointly, address more than $5 \%$ of the cells in only eight of the 17 SDGs (i.e., not even half of them).

All of this suggests that, even though there is an important difference in the scopes of the SDGs and the rating systems that should not be ignored, the latter do not, in any event, properly address the issue of sustainability, as defined by the UN, including in relation to the goals where there should be greater alignment. This is also evidenced by the higher value for G7 (energy) in the union column (30.67\%). Indeed, even though a very generous inclusiveness criterion was adopted for this goal, which is the one addressed most by the protocols, the three systems jointly cover less than a third of the cells considered in the matrix. This suggests that these low values may not just be due to a difference in scopes, and that they are instead an issue in the way these rating systems fit within a global sense and promotion of sustainability.

\section{CONCLUSION}

This article describes the development of an evaluation matrix, with the UN's 17 Sustainable Development Goals (SDGs), and 169 related targets used as distinct benchmarks against which to measure the sustainability of a building (residential; office) or item of infrastructure. The matrix examines five different scalelevels simultaneously: operator/worker, user/inhabitant, neighbourhood, city and world. Also considered for each SDG target are the following phases: pre-use (A1-A5), use (B1-B7) and end-of-life (C1-C4, D) (EN, 2013). In addition, each target is subdivided into three further categories-environment, economy and society-in accordance with the Triple Bottom Line (TBL) paradigm, which describes sustainability in terms of returns on investment and shareholder value, including any environmental and social dimensions (Slaper, 2011).

The matrix highlights how the three different rating systems considered, LEED, BREEAM and ITACA, align with the objectives of the SDGs, and also compares them with each other. LEED was found to be the best-performing system of the three from the point of view of coverage of the SDGs, with a mean score of $5.48 \%$ (vs. $3.29 \%$ for BREEAM and $2.13 \%$ for ITACA) and a median of $3.70 \%$ (vs. 0 for both BREEAM and ITACA). This is probably due to the more holistic approach adopted by LEED, which, in general terms, covers all 17 SDGs; BREEAM and ITACA, meanwhile, fail to cover nine and ten of them, respectively. The SDGs in relation to which these two rating systems had a score of 0 are: G1 (no poverty), G2 (no hunger), G4 (education), G5 (gender equality), G8 (work and growth), G10 (inequalities), G14 (life below water), G16 (peace and justice) and G17 (partnership).

The union values demonstrate that only a few cells are covered in the matrix by the three systems, with scores ranging from $30.67 \%$ for G7 (energy) to $0.37 \%$ for G1 (no poverty). On the other hand, the intersection column shows the values achieved by the global intersection confirming the trend, with scores of $0 \%$ for 11 of 17 SDGs (mean: $0.33 \%$; median: 0 ). At $1.78 \%$, the highest scores were observed for G7 (energy), which means that this SDG is the one that is best addressed by the three rating systems.

The analysis of the interplay among the SDGs and the three GBRSs suggests that present-day rating systems do not properly address sustainability as defined by the UN. On the one hand, these differences are in part due to their different scopes. Indeed, the GBRSs were designed to meet specific requirements that are strictly related to building sustainability and the real estate market; meanwhile, the SDGs are an invitation to countries around the world to adopt certain policies. On the other hand, the low alignment measured by systematically mapping the GBRSs onto the SDGs-and vice-versa-shows that many of the subgoals related to the building industry could be better targeted and addressed, in particular in relation to specific stakeholders and lifecycle stages.

In all likelihood, it ultimately appears that, even when accounting for the differences in the scopes of GBRSs and SDGs, there may still be issues in the way these rating systems fit within a global and holistic view of sustainability. As intergovernmental organizations and policy-makers progress toward agreeing on a common agenda on how best to produce a blueprint for innovative sustainability paradigms, rating systems can be updated to become a powerful instrument and bridge toward such progress in key industries like the construction sector. As a further development prompted by these findings, an experimental rating system to foster a wider sustainable application of the SDGs may be envisaged.

\section{DATA AVAILABILITY STATEMENT}

The raw data supporting the conclusions of this article will be made available by the authors, without undue reservation. 


\section{AUTHOR CONTRIBUTIONS}

All authors listed have made a substantial, direct, and intellectual contribution to the work and approved it for publication.

\section{REFERENCES}

Ade, R., Rehm, M., and Ade, R. (2019). The Unwritten History of green Building Rating Tools: a Personal View from Some of the 'founding Fathers'. Building Res. Inf. 48, 1-17. doi:10.1080/09613218.2019.1627179

Alawneh, R., Ghazali, F., Ali, H., and Sadullah, A. F. (2019). A Novel Framework for Integrating United Nations Sustainable Development Goals into Sustainable Non-residential Building Assessment and Management in Jordan. Sust. Cities Soc. 49, 101612. doi:10.1016/j.scs.2019.101612

Ameen, R. F. M., Mourshed, M., and Li, H. (2015). A Critical Review of Environmental Assessment Tools for Sustainable Urban Design. Environ. Impact Assess. Rev. 55, 110-125. doi:10.1016/j.eiar.2015.07.006

Asdrubali, F., Baldinelli, G., Bianchi, F., and Sambuco, S. (2015). A Comparison between Environmental Sustainability Rating Systems LEED and ITACA for Residential Buildings. Build. Environ. 86, 98-108. doi:10.1016/j.buildenv.2015.01.001

Atanda, J. O., and Öztürk, A. (2020). Social Criteria of Sustainable Development in Relation to green Building Assessment Tools. Environ. Dev. Sustain. 22, 61-87. doi:10.1007/s10668-018-0184-1

Awadh, O. (2017). Sustainability and green Building Rating Systems: LEED, BREEAM, GSAS and Estidama Critical Analysis. J. Build. Eng. 11, 25-29. doi:10.1016/j.jobe.2017.03.010

Bovea, M. D., and Powell, J. C. (2016). Developments in Life Cycle Assessment Applied to Evaluate the Environmental Performance of Construction and Demolition Wastes. Waste Manag. 50, 151-172. doi:10.1016/j.wasman.2016.01.036

Cen, E. C. F. S. (2013). EN 15804:2013 - Standards Publication Sustainability of Construction Works - Environmental Product Declarations - Core Rules for the Product Category of Construction Products. International Standard, 70, Brussels.

Chandrakumar, C., and McLaren, S. J. (2018). Towards a Comprehensive Absolute Sustainability Assessment Method for Effective Earth System Governance: Defining Key Environmental Indicators Using an Enhanced-DPSIR Framework. Ecol. Indicators 90, 577-583. doi:10.1016/j.ecolind.2018.03.063

Cordero, A. S., Melgar, S. G., and Márquez, J. M. A. (2019). Green Building Rating Systems and the New Framework Level(s): A Critical Review of Sustainability Certification within Europe. Energies 13, 1-25. doi:10.3390/ en 13010066

Dalrymple, G. B. (1991). Age of the Earth USGS. Retrieved from: https://pubs.usgs. gov/gip/geotime/age.html.

Doan, D. T., Ghaffarianhoseini, A., Naismith, N., Zhang, T., Ghaffarianhoseini, A., and Tookey, J. (2017). A Critical Comparison of green Building Rating Systems. Build. Environ. 123, 243-260. doi:10.1016/j.buildenv.2017.07.007

European Commission - Joint Research Centre - Institute for Environment and Sustainability (2010). International Reference Life Cycle Data System (ILCD) Handbook: Analysing of Existing Environmental Impact Assessment Methodologies for Use in Life Cycle Assessment, 115. Luxrnbourg: European Commission.

European Commission (2012). Strategy for the Sustainable Competitiveness of the Construction Sector and its Enterprises. COM 66, 37-39.

European Commission (2019). Construction and Demolition Waste (CDW). Retrieved from: https://ec.europa.eu/environment/waste/construction_ demolition.htm\%0A (Accessed March 09, 2021).

European Committee for Standardization (2011). UNE-EN 15978:2011 Sustainability of Construction Works - Assessment of Environmental Performance of Buildings - Calculation Method. Brussels: International Standard.

Global (2017). Reporting Initiative and UN Global Compact and the World Business Council for Sustainable Development. SDG Compass. Retrieved from: www. sdgcompass.org.

Hák, T., Janoušková, S., and Moldan, B. (2016). Sustainable Development Goals: A Need for Relevant Indicators. Ecol. Indicators 60, 565-573. doi:10.1016/ j.ecolind.2015.08.003

\section{FUNDING}

PROgettare in SostenibilITà: qualificazione e digitalizzazione in edilizia (POR CAMPANIA FESR 2014-2020), Grant number CUP B63D18000290007.

Hamedani, A. Z., and Huber, F. (2012). A Comparative Study of DGNB, LEED and BREEAM Certificate Systems in Urban Sustainability. WIT Trans. Ecol. Environ. 155, 121-132. doi:10.2495/SC120111

IEA. (2019). Global Status Report for Buildings and Construction. Nairobi: UNEP. doi:10.1038/s41370-017-0014-9

Illankoon, I. M. C. S., Tam, V. W. Y., Le, K. N., and Shen, L. (2017). Key Credit Criteria Among International green Building Rating Tools. J. Clean. Prod. 164, 209-220. doi:10.1016/j.jclepro.2017.06.206

ISO (2006a). Environmental Management - Life Cycle Assessment - Principles and Framework. 2nd ed. Geneva: ISO. ISO 14040; 2006-07-01

ISO (2006b). "Environmental Management - Life Cycle Assessment Requirements and Guidelines," in ISO 14044 Enviro Mgmt LCA Requirements and Guidelines. 1st ed., 1. Geneva: ISO.ISO 14044; 2006-07-01

Kara, S., Hauschild, M. Z., and Herrmann, C. (2018). Target-Driven Life Cycle Engineering: Staying within the Planetary Boundaries. Proced. CIRP 69, 3-10. doi:10.1016/j.procir.2017.11.142

Keeble, B. R. (1988). The Brundtland Report: 'Our Common Future'. Med. War 4 (1), 17-25. doi:10.1080/07488008808408783

Khan, M., Sepasgozar, S., Wang, C. C., and Data, S. B. (2018). Evolution of Building Rating Tools: A Next Generation Rating Model Evolution of Building Rating Tools: A Next Generation Rating Model. Victoria: Deakin University.

Laurent, A., Molin, C., Owsianiak, M., Fantke, P., Dewulf, W., Herrmann, C., et al. (2019). The Role of Life Cycle Engineering (LCE) in Meeting the Sustainable Development Goals - Report from a Consultation of LCE Experts. J. Clean. Prod. 230, 378-382. doi:10.1016/j.jclepro.2019.05.129

Lee, W. L. (2013). A Comprehensive Review of Metrics of Building Environmental Assessment Schemes. Energy and Build. 62, 403-413. doi:10.1016/ j.enbuild.2013.03.014

Li, Y., Chen, X., Wang, X., Xu, Y., and Chen, P.-H. (2017). A Review of Studies on green Building Assessment Methods by Comparative Analysis. Energy and Build. 146, 152-159. doi:10.1016/j.enbuild.2017.04.076

Marjaba, G. E., and Chidiac, S. E. (2016). Sustainability and Resiliency Metrics for Buildings - Critical Review. Build. Environ. 101, 116-125. doi:10.1016/ j.buildenv.2016.03.002

Martin, J., Henrichs, T., and Eea (2015). The European Environment: State and Outlook 2015: Synthesis. Luxembourg: EEA. doi:10.2800/4577310.1109/ radar.2015.7131004

Muff, K., Kapalka, A., and Dyllick, T. (2017). The Gap Frame - Translating the SDGs into Relevant National Grand Challenges for Strategic Business Opportunities. Int. J. Manag. Edu. 15 (2), 363-383. doi:10.1016/j.ijme.2017.03.004

Nguyen, B. K., and Altan, H. (2011). Comparative Review of Five Sustainable Rating Systems. Proced. Eng. 21 , 376-386. doi:10.1016/j.proeng.2011.11.2029

Ofori-Boadu, A., Owusu-Manu, D. G., Edwards, D., and Holt, G. (2012). Exploration of Management Practices for LEED Projects. Struct. Surv. 30 (2), 145-162. doi:10.1108/02630801211228743

Pedersen, C. S. (2018). The Un Sustainable Development Goals (SDGs) Are a Great Gift to Business!. Proced. CIRP 69, 21-24. doi:10.1016/j.procir.2018.01.003

Protocollo, I. T. A. C. A. (2004). Retrieved from: https://www.itaca.org/ valutazione_sostenibilita.asp.

Reed, J. D. (2014). “Introduction,” in Virgil's Gaze, 1-15. doi:10.1515/9781400827688.1

Rushby, A. J., Claire, M. W., Osborn, H., and Watson, A. J. (2013). Habitable Zone Lifetimes of Exoplanets Around Main Sequence Stars. Astrobiology 13 (9), 833-849. doi:10.1089/ast.2012.0938

Slaper, T. F. (2011). The Triple Bottom Line: What Is it and How Does it Work? the Triple Bottom Line Defined. Indiana Business Rev. 86 (1), 4-8. Retrieved from: http://www.ibrc.indiana.edu/ibr/2011/spring/article2.html.

Small, N., Munday, M., and Durance, I. (2017). The challenge of Valuing Ecosystem Services that Have No Material Benefits. Glob. Environ. Change 44, 57-67. doi:10.1016/j.gloenvcha.2017.03.005 
UNI/PdR 13 (2019). UNI/PdR 13 - Sostenibilità ambientale nelle costruzioni Strumenti operativi per la valutazione della sostenibilità - Edifici residenziali. Vierra, S. (2019). Green Building Standards and Certification Systems.

Weidema, B., Goedkoop, M., and Mieras, E. (2018). Making the SDGs Relevant to Business. Retrieved from: https://www.pre-sustainability.com/download/ Making-the-SDGs-relevant-to-business_public-version.pdf.

Willis, K. (2018). “The Sustainable Development Goals,"in The Routledge Handbook of Latin American Development New York, 121-131. doi:10.4324/9781315162935-11

Yudelson, J., and Meyer, U. (2013). The World's Greenest Buildings: Promise versus Performance in Sustainable Design. Abingdon: Routledge. doi:10.4324/ 9780203082164 CrossRef Full Text
Conflict of Interest: The authors declare that the research was conducted in the absence of any commercial or financial relationships that could be construed as a potential conflict of interest.

Copyright (c) 2021 Vitale, Alfano, Pastore, Menna, Maffettone and Asprone. This is an open-access article distributed under the terms of the Creative Commons Attribution License (CC BY). The use, distribution or reproduction in other forums is permitted, provided the original author(s) and the copyright owner(s) are credited and that the original publication in this journal is cited, in accordance with accepted academic practice. No use, distribution or reproduction is permitted which does not comply with these terms. 